about 90 might still be alive at the end of that period, compared with perhaps 78 among 100 patients not so treated. Among the same 100 men, on the average 86 would have escaped reinfarction compared with approximately 62 in those not given anticoagulants. On the other hand, perhaps 1 of the 100 treated men would have suffered a fatal cerebrovasicular accident and eight a potentially serious haemorrhage. These rough indications of possible benefit and risk will vary according to age and clinical conditions, but they may serve to put in perspective the possible benefits and risks of the continued administration of anticoagulant drugs.

\section{Summary and Conclusions}

An interim report has already been made (Report to M.R.C., 1959) on the results of a controlled trial of long-term anticoagulant therapy in 383 patients who had suffered one or more previous myocardial infarctions. This described the clinical progress of those patients from November 1955 to the end of 1958. New patients were admitted to the trial between November 1955 and March 1958. The subsequent progress of the patients up to May 1960 is described in the present report.

In this controlled trial a comparison was made between the clinical progress of patients given sufficient phenindione to prolong the one-stage "prothrombin " time to two to two and a half times the control value (high-dosage group) with the experience of a similar series of patients given tablets containing $1 \mathrm{mg}$. of phenindione (low-dosage group).

In May 1960 there was practically no difference in the frequency of death in male patients aged 55 and over and in females. Among men below 55 there was still a difference in mortality from non-violent causes-18 deaths among 69 men on the low dosage as compared with 9 out of 74 men on high dosage. This difference failed to reach conventional levels of statistical significance.

When fatal and non-fatal reinfarctions were considered together there were technically significant reductions in males in both age-groups. Below 55 years the rate was down to a quarter of the control level and in the older men to a half of the control level. The number of female patients was too small to permit firm conclusions, but the figures do not show any difference in reinfarction rate. The electrocardiographic evidence of reinfarction was submitted to physicians who did not know the treatment group. There was no evidence that reinfarction was being more readily diagnosed in the low-dosage group.

In May 1960 (after two to five years of treatment) the trial was discontinued in the low-dosage patients and they were treated as wished by their attendant physicians. Since the early advantage in mortality in favour of high-dosage therapy had become progressively less, it was thought justifiable at this stage to assess the risks, if any, of transfer of patients from high-dosage to low-dosage regimes. Though there were more non-fatal reinfarctions on the follow-up of this new low-dosage group as compared with the new high-dosage group, these did not reach significant levels. The deaths from all causes and the deaths from reinfarction were practically the same in the two groups.

The implications of these results are discussed in relation to the findings in other similarly controlled trials.

The Working Party is indebted to Evans Medical Supplies Ltd., Imperial Chemical (Pharmaceuticals) Ltd., and Duncan Flockhart and Co. Ltd. for the provision of bulk supplies of phenindione, which were tableted and distributed by Evans Medical Supplies Ltd. for the purpose of this trial, and to Miss L. M. Colwell for statistical assistance.

\section{REFERENCES}

Armitage, P. (1960). Sequential Medical Trials. Blackwell, Oxford. Aspenström, G. (1962). Nord. Med., 68, 982. Borchgrevink, C. F. (1960). Acta med. scand., 168, Suppl. No. 359. - (1962). Lancet, 1, 449.

Bierkelund, C. J. (1957). Acta med. scand., 158, Suppl. No. 330.

(1961). "Anticoagulants and fibrinolysins." Proceedings of Symposium Toronto, edited by R. L. MacMillan and J. F. Mustard. Posium Toronto,

Clausen, J., Andersen, P. E., Andresen, P., Gruelund, S., Harslof, E., Andersen, U. H., Jorgensen, J., and Mose, C. (1961). Ugeskr. Lag., 123, 987.

Davies, L. G. (1958). Brit. Heart F., 20, 153.

Harvald, B., Hilden, T., Letman, H., Lund, E., Thaysen, E. H., and Worning, H. (1961). Ugeskr. Lag., 123, 983.

Lovell, R. R. M., Denborough, M. A., and Nestel, F. J. (1962). Personal communication from the Royal Melbourne Hospital

communication from the Royal Melbourne Hospital. med. Ass. F., 83, 567 .

Report to Medical Research Council (1959). Brit. med. F., 1, 803.

\title{
Eight Years' Experience with Oral Contraception and an Analysis of Use of Low-dosage Norethisterone*
}

\author{
EDWARD T. TYLER, $†$ M.D.
}

Brit. med. F., 1964, 2, 843-847

In 1956 the Los Angeles Planned Parenthood Center initiated the first United States study of oral contraception and embarked on comprehensive and detailed investigations of this form of birth control, very shortly after Pincus began his pioneering work in Puerto Rico. The results of these studies of the effects of progestin-oestrogen combinations have been reported by my associates and me periodically (Tyler and Olson, 1959 ; Tyler et al., 1961, 1964 ; Proceedings, 1963 ; Tyler, 1964). It was obvious quite early, and is now definitely established, that potent synthetic progestational compounds with sufficient oestrogen

\footnotetext{
- Presented at the Annual Meeting of the Society for the Study of Fertility, Nottingham, England, July 1963.

† President, American Association of Planned Parenthood Physicians and Medical Director, Los Angeles Planned Parenthood Centers.
}

can be satisfactorily employed for contraceptive purposes on a 20-day schedule starting on the fifth day of each cycle and are as close to $100 \%$ effective as anything in medicine can be.

After a few years' use of relatively high doses of these combinations we began using a variety of lower-dosage forms (as well as new agents) in an attempt to modify some of the sideeffects and also provide less medication and more inexpensive products. The current report relates to certain of our experience with various preparations, as well as some of the vicissitudes of oral contraception in the United States.

Our initial experiences with oral contraception involved the use of a tablet containing $10 \mathrm{mg}$. of norethisterone with a variable amount of mestranol (ethinyl-oestradiol, 3-methyl ether) not exceeding $0.06 \mathrm{mg}$. (The variation in oestrogen con- 
tent was related to the manufacturing problem, at the time, of producing norethisterone uncontaminated by oestrogen. Subsequently, the oestrogenic component was fixed at $0.06 \mathrm{mg}$.) Finding the $10-\mathrm{mg}$. norethisterone tablet a potent and effective dosage, we soon satisfactorily added the $10 \mathrm{mg}$. norethynodrel preparation to our study. At the end of about two years we decided to try combinations containing $5 \mathrm{mg}$. of norethisterone or norethynodrel with $0.075 \mathrm{mg}$. of mestranol. When, after a relatively short time, it was apparent that the $5 \mathrm{mg}$. dosage combinations were effective, we initiated studies of preparations containing $2 \mathrm{mg}$. of northisterone with $0.1 \mathrm{mg}$. of mestranol and $2.5 \mathrm{mg}$. of norethynodrel with $0.1 \mathrm{mg}$. mestranol.

Several reports have appeared in the British literature concerning the $2.5-\mathrm{mg}$. norethynodrel tablet, but proportionately fewer have documented the 2-mg. norethisterone tablet. Since our experience with this low-dosage preparation is quite extensive, I have analysed our data below.

In evaluating any low-dosage contraceptive combination it is of course important to obtain preliminary clinical pharmacology to prove ovulation-inhibiting properties. When one is employing a progestogen-oestrogen combination for ovulation suppression there are very limited criteria which may be used to provide evidence of anovulation. Since endometrial histology is distorted by the medication, biopsies provide little practical information concerning ovulation (Goldfarb, 1964). Similarly, these hormonal agents alter cervical mucous and vaginal-smear patterns so that the latter are not usable (Tyler and Olson, 1958). The only current practical test that can be employed is the pregnanediol determination, since most synthetic progestins do not metabolize through pregnanediol. Our method of checking pregnanediol excretion is to have the patient collect 12-hour urine for 10 nights during the theoretical post-ovulatory phase. If less than $1 \mathrm{mg} . / 24$ hours is excreted this is good indirect evidence of anovulation, particularly if the chromatographic curve is not typical of pregnanediol.

In our original investigations of the norethisterone-mestranol 2-mg. tablet, we studied about two dozen women cyclically to make sure that ovulation was inhibited, as had been obtained with the higher dose. In the series of two dozen women there was only one instance in which pregnanediol-excretion levels were in a range where the occurrence of ovulation might have been suspected. This in itself did not deter us in evaluating the contraceptive use of the 2-mg. preparation, because it is well known that ovulation inhibition alone does not account for the contraceptive effectiveness of the progestogen-oestrogen preparations. Since there are the additional safeguards of alteration of cervical mucus and distortion of the endometrium, both of which inhibit conception, we were fairly confident that the low-dosage preparation would work quite well.

Accordingly, approximately three years ago we began a clinical trial of the 2-mg. norethisterone-mestranol tablet. $\ddagger$ At that time this was the lowest progestin dosage that we had been employing for contraceptive purposes. The most striking thing we noted about the low-dosage form was that it was extremely well tolerated. In this connexion it should be emphasized that, since oral contraception has been in use at our clinic for several years, patients in the area know quite a bit about it, and most preparations are now accepted with little concern about their possible side-reactions. Early in our studies this was not the case and many more patients complained of various side-effects, the majority of which could probably be attributed to a lack of assurance about this type of contraception, and both patients and doctors were not convinced that it was a type of contraception to employ. But as confidence in this method was achieved the incidence of side-effects as complaints has, of course, dropped markedly. This appears to be the experience in other centres as well.

$¥$ Ortho-Novin, supplied to us for study by the Ortho Pharmaceutical Corp., Raritan, N.Y.

\section{Toxicity Studies}

Since there have been certain reservations on the part of many practitioners regarding effects of these chemicals on various body functions we have made it a point to investigate possible changes in blood chemistry as well as certain alterations in hormone assays. During this study we spot-checked a substantial number of patients and did rather intensive blood-chemistry investigations on this group. There were 125 patients on the 2-mg. norethisterone tablets who had the following battery of blood-chemistry studies : blood urea nitrogen, glucose, cholesterol, calcium, phosphorus, potassium, bromsulphthalein (B.S.P.), serum glutamic pyruvic transaminase, serum proteins, complete blood counts, and protein-bound iodine. There were fair percentages of abnormal findings in several of the tests performed. The significance of these was rather obscure, and hence it was decided to go into this matter further. One thought that occurred to us was the possibility that certain abnormalities might be related to the time in the cycle at which blood was drawn. We therefore analysed the findings relative to cycle-day of drawing of blood for patients on the 2-mg. tablet who had B.S.P. tests. Fig. 1 illustrates the distribution of abnormal findings. As may readily be observed, a preponderance of patients having abnormalities had blood taken during the latter, or usual luteal, phase of the cycle. On the other hand, when we also evaluated our serum phosphorus findings in the same manner it was evident that abnormal findings were fairly evenly distributed over the entire cycle (Fig. 2). The latter circumstances therefore cast doubt about a cyclic effect of these compounds on blood values unless this cyclic effect was specific for certain particular chemical agents.

We also wondered at this point whether the specific progestogen had a relation to abnormal values, and we therefore studied a substantial number of patients who were taking a variety of the progestational agents. At that particular time we also had under investigation norethisterone acetate, ethy-

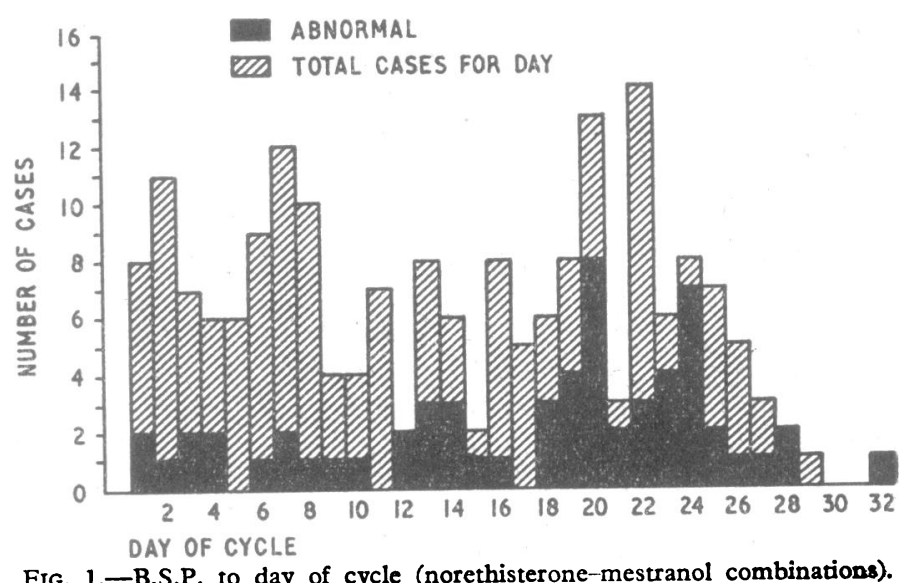

FIG. 1.-B.S.P. to day of cycle (norethisterone-mestranol combinations).

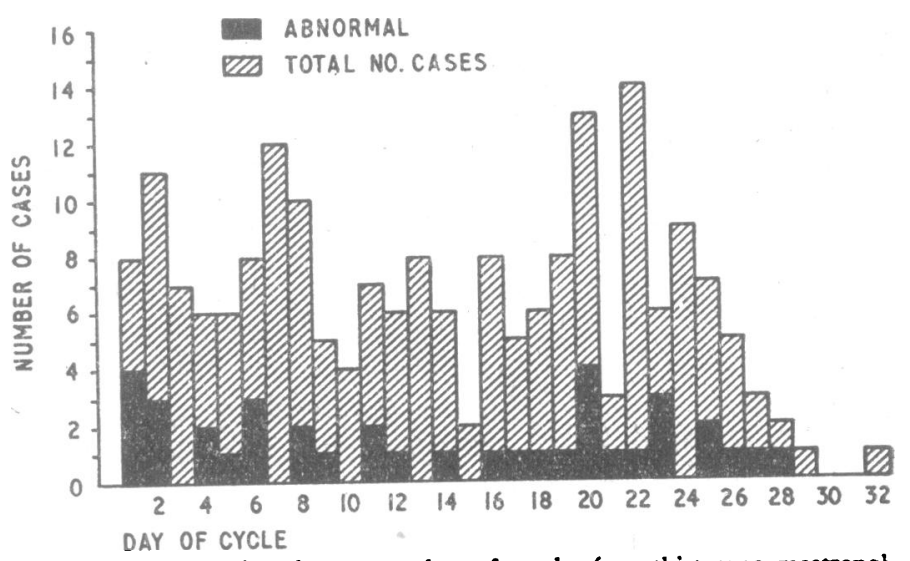

FIG. 2.-Serum phosphorus to day of cycle (norethisterene-mestranol combinations) 
nodiol diacetate (Ovulen), chlormadinone and norethisterone (Sequential), and medroxyprogesterone preparations (such as Provest, which is medroxyprogesterone with ethinyl oestradiol). Fig. 3 illustrates the findings with different agents so far as the B.S.P. test is concerned, and it may be observed that there were small percentages of abnormal findings associated with virtually each compound used. The same situation was true for the transaminase levels (Fig. 4). This therefore gave us the impression that the alterations in the blood-chemistry findings were not specific for any one compound but appeared to be connected with this particular type of hormone administration in general.

It further appeared possible that the abnormal findings observed might be comparable to those that appeared in the pregnancy state, since it has often been suggested that progestogen-oestrogen oral contraception produces a pseudopregnancy state. We therefore undertook to study a substantial group of controls among normal pregnant women who were not taking medication of this type. There were several abnormalities in this particular group of patients that were comparable to those among patients taking contraceptive pills.

While we have not completed these investigations, our data thus far seem to suggest that though some contraceptive patients
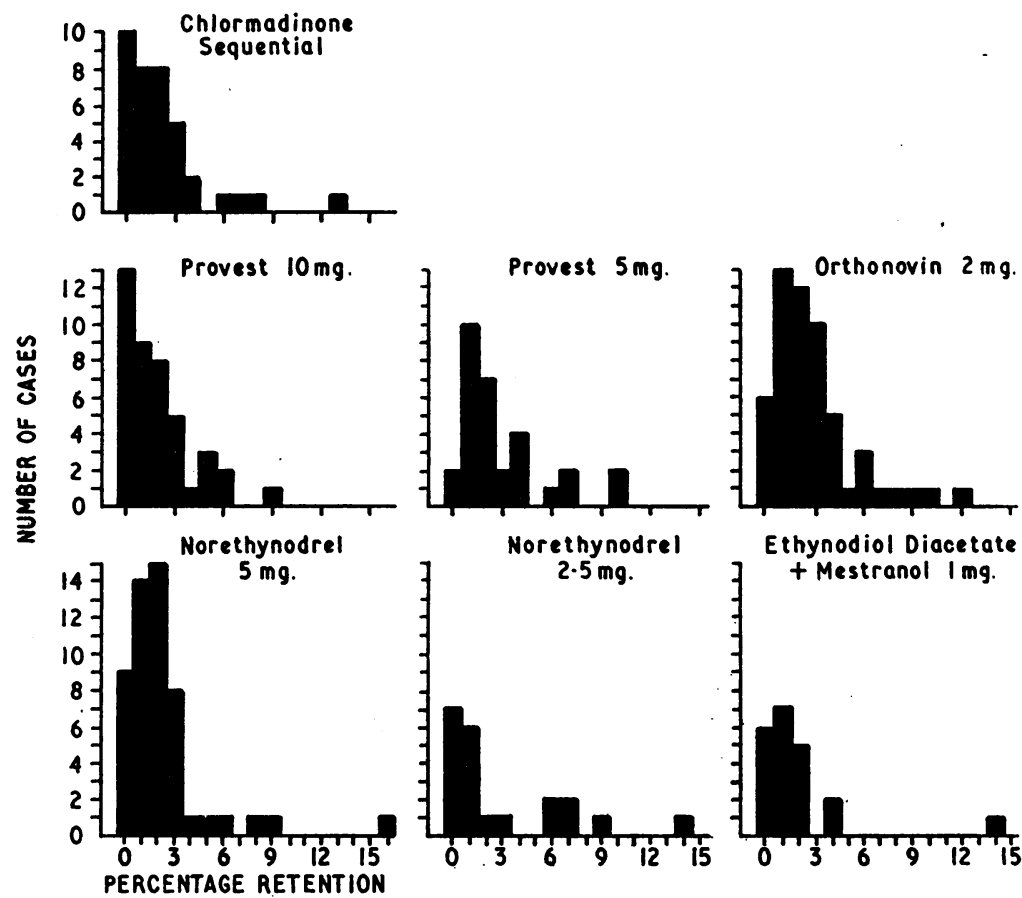

Ethynodiol Diacetate

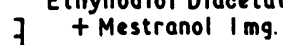

FIG. 3.-B.S.P. percentage retention (through April 1963).
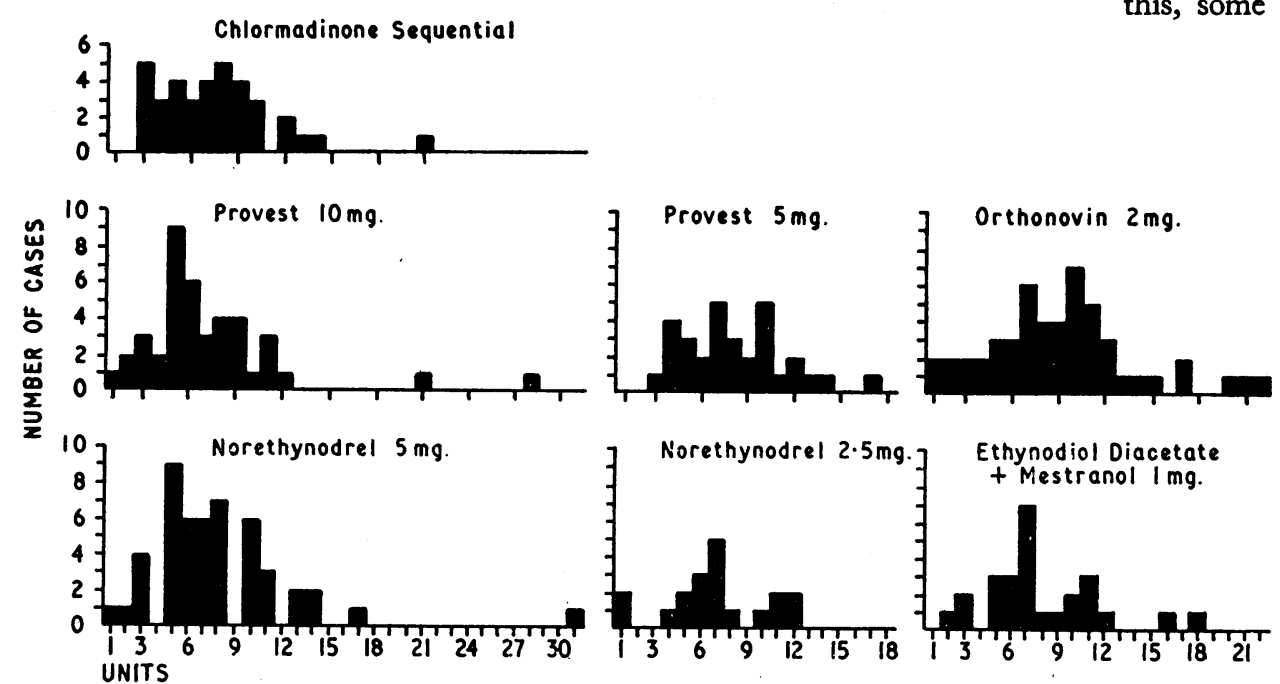

FIG. 4.-S.G.P.T. units (cases studied through Aprll 1963). show abnormal findings in certain blood-chemistry characteristics these findings may be comparable to what often occurs during pregnancy. There is also a possibility that abnormal test findings might not actually represent abnormal function of the organs involved. At present, of course, this is merely a conjecture, because it will take substantially more patients as well as more elaborate studies (including blood volumes, T3 tests, etc.) and confirmatory results in a number of centres before the matter can be completely resolved. One limiting factor in resolving this question is the fact that most patients at the present time feel that they are on an accepted method of birth control and do not welcome the idea of having substantial amounts of blood drawn repeatedly for experimental studies. This has a tendency to create doubt in the minds of the patient and also is a rather involved matter from the standpoint of contraceptive-clinic policy. Naturally, patients in a clinic who are using vaginal methods do not have the same demands made upon them, and patients using oral contraception feel that they can go to any doctor and obtain the pills without the need for the involved studies that we are conducting. This also holds for our policy of getting repeat Papanicolaou smears and endometrial biopsies on these patients at regular intervals. We feel it imperative to see that these are done so as to provide data on lengterm effects; yet the fact that patients now may simply obtain a prescription for a year's supply, or more, of oral contraceptives with no study makes it difficult to continue this type of needed detailed investigation.

A matter that has, of course, been a cause for concern with oral contraception is the question of possibly related thrombophlebitis and pulmonary embolism. In our experience at the Los Angeles Planned Parenthood Center, using a substantial number of contraceptive combinations over a period of eight years, we have had no case of thrombophlebitis or embolism; and this work has involved well over 5,000 patients who have been under treatment and about 100,000 cycle-months of therapy using various preparations.

In any event, when the first cases of embolism were reported in the U.S.A. we felt it imperative to look into the matter, and so we sought the assistance of haematologists who were familiar with coagulation problems. It should be emphasized, as has been mentioned repeatedly, that there are no practical tests which are adequate for detecting changes in the blood that would definitely determine increasing tendencies toward spontaneous thrombosis or even decreasing tendencies. Despite this, some three yeurs ago we again spot-checked about 50 patients on various contraceptive preparations and had the co-operation of haematologists-Dr. A. Rappaport, Dr. A. Samuels, and Dr. H. Henstell-in these endeavours. While the studies involved several preparations and various different coagulation tests, it should be mentioned that in no instance were changes observable that would definitely demonstrate drug-induced increased tendencies for the blood to clot spontaneously intravascularly (Henstell, 1963 ; Samuels and Lepowsky, 1963).

In view of the fact that a special committee appointed by the U.S. Food and Drug Administration to study the thrombophlebitis problem did not urge the pursuit of detailed 
blood-coagulation studies we discontinued these because of the expense involved, the great inconvenience to the patient, as well as the fact that it was apparent this was not going to help us materially in providing an answer to the question. I recently reviewed this subject (Tyler, 1963).

\section{Summary of Results with Norethisterone 2-mg. Tablets}

By 1 March 1964435 patients had used the 2-mg. norethisterone tablets in our clinic. The total number of cycles of use was 6,455 , with an average of 14.8 cycles per patient. The average age of the patients in our series was 26.8 , and previous pregnancies averaged 3.8. As may be noted in Fig. 5, the longest period of use of the $2-\mathrm{mg}$. tablet was 39 cycles, and 79 patients had been on the medication for three years or more. Of the 93 patients who dropped out of the study 10 $(2.2 \%)$ did so because of medication-related reasons (Table I). The remaining $83(19.0 \%)$ left the study for such reasons as moving from the area, planning a pregnancy, etc.

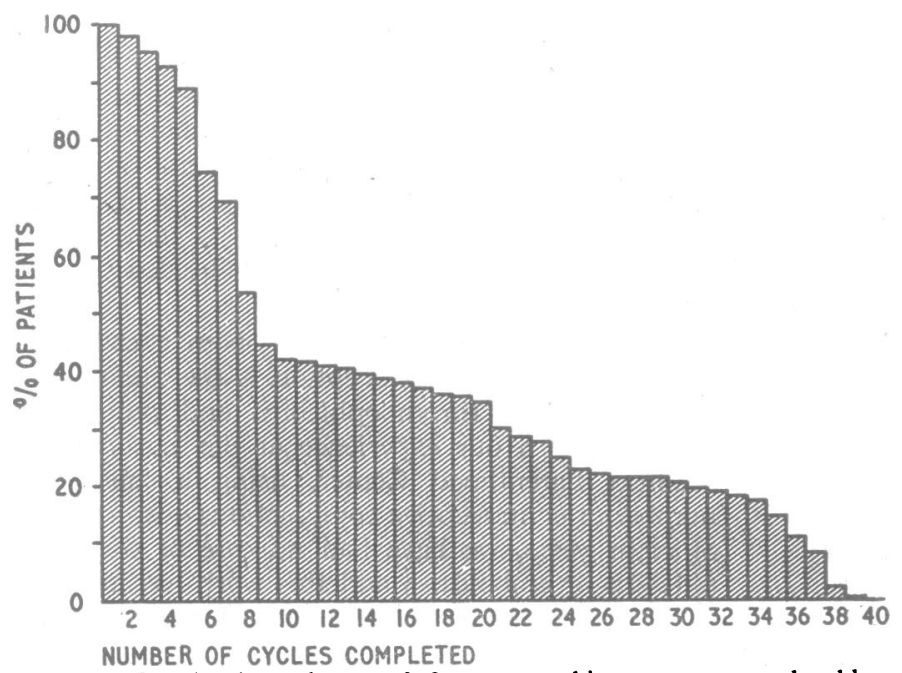

FIG. 5.-Distribution of use of $2-\mathrm{mg}$. norethisterone-mestranol tablets by cycles completed.

TABLE I.-Reasons for Discontinuing Medication in 93 Cases

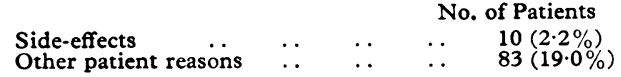

Since side-effects are common with all oral contraceptives we have analysed our data relative to the occurrence of breakthrough bleeding, nausea, dysmenorrhoea, and weight changes, and have also tabulated the effect on the menstrual flow. So far as nausea is concerned, $18(4.1 \%)$ of the 435 patients experienced this side-effect in a total of 19 cycles. This gave the very low cycle-incidence of $0.2 \%$. The distribution of occurrence of nausea related to cycles is given in Fig. 6.

Break-through bleeding (including spotting) also occurred relatively infrequently; $85(19.5 \%)$ patients had some breakthrough bleeding in 157 cycles, with a cycle incidence of only $2.4 \%$. The percentages per cycle related to the number of

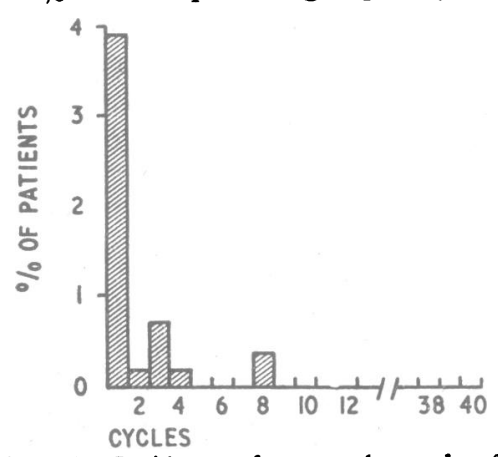

Fig. 6.-Incidence of nausea by cycle of medication with 2-mg. norethisteronemestranol tablets. since so many women tend to gain or lose weight. On the other hand, the progestogens are usually somewhat anabolic, and it might be expected that there would be a tendency to gain in weight. As shown in Table II, 108 women (26.6\%) had a gain of over $5 \mathrm{lb}$. (2.27 kg.), while only $31(7.5 \%)$ lost $5 \mathrm{lb}$. or more. Gains or losses of less than $5 \mathrm{lb}$. are probably not significant enough to consider statistically, but these are also noted in Table II. When weight gain did occur, in the majority of instances it was less than $10 \mathrm{lb}$. $(4.5 \mathrm{~kg}$.). Because of the

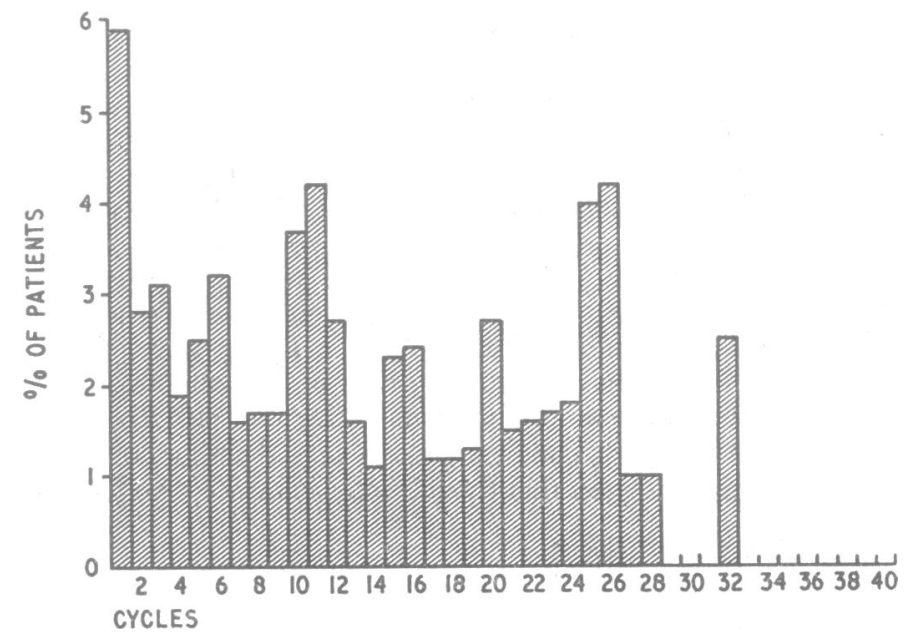

FIG. 7.- Incidence of break-through bleeding and spotting by cycle of medication with 2-mg. norethisterone-mestranol tablets.

TABLE II.-Weight Change in Patients Taking $2 \mathrm{mg}$. Norethisterone-

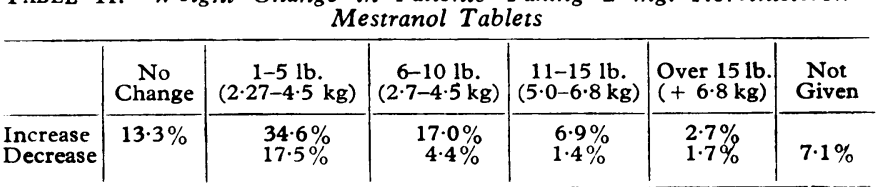

obvious tendency for the weight to increase when oral contraception is used we have tried to assist patients, on all preparations, in controlling their weight, by supplying appetite suppressants when needed, and these have prove effective, as will be detailed elsewhere.

Anti-ovulatory therapy is supposed to control dysmenorrhoea, and we have been interested in this effect in our investigations. Of the 435 patients in the 2-mg. norethisterone study, 420 $(97.6 \%)$ were not bothered by dysmenorrhoea prior to starting pills, and only $10(2.1 \%)$ could be evaluated according to increase or decrease in discomfort. Surprisingly, six patients showed increased dysmenorrhoea, while three had less (Table III). These are insignificant percentages $(1.3 \%$ and $0.6 \%$ ) in any case, but we would have expected comparatively more patients to show improvement rather than increase in dysmenorrhoea.

So far as effect on menstrual flow is concerned, the withdrawal bleeding after use of pills was essentially the same as prior menses in the vast majority of patients $(351$, or $82.2 \%$ ). Table III indicates that, of those reporting a change in flow, almost five times as many had lighter flow as had increased bleeding.

In this group of 435 patients, covering 6,455 cycles of use of the $2-\mathrm{mg}$. norethisterone tablet, there were no pregnancies. It should be noted that a few patients experienced amenorrhoea, or lack of withdrawal bleeding, sometimes for several cycles ; but repeated examinations, with frequent pregnancy tests, confirmed the absence of pregnancy.

\begin{tabular}{|c|c|c|c|c|c|}
\hline TABLE III. & & $\begin{array}{l}\text { ect of 2-mg. N } \\
\text { ysmenorrhoea a }\end{array}$ & $\begin{array}{l}\text { ethisterone-mes } \\
\text { Menstrual Fl }\end{array}$ & . & Tablets on \\
\hline $\begin{array}{l}\text { Dysmenorrhoea } \\
\text { Less ... } \\
\text { Same .. } \\
\text { Increased } \\
\text { None ... } \\
\text { Unknown }\end{array}$ & $\begin{array}{l}\ldots \\
\cdots \\
\cdots \\
\cdots\end{array}$ & $\begin{aligned} \text { No. of Patients } \\
3(0.7 \%) \\
1(0.2 \%) \\
6(1 \cdot 4 \%) \\
420(97 \cdot 7 \%) \\
5(1 \cdot 1 \%)\end{aligned}$ & $\begin{array}{l}\text { Menstrual Flow } \\
\text { Lighter } \\
\text { Same . } \\
\text { Increased } \\
\text { Unknown }\end{array}$ & $\begin{array}{l}\ldots \\
\cdots \\
\cdots\end{array}$ & $\begin{array}{l}\text { No. of Patients } \\
63(14.7 \%) \\
351(82.2 \%) \\
13(3.0 \%) \\
8(1.8 \%)\end{array}$ \\
\hline
\end{tabular}




\section{Discussion}

It has been quite definitely established that progestogenoestrogen oral contraception is very effective with certain recognized but not serious side-effects. Our more recent efforts, and those of most other investigators of these compounds, have taken two major directions: (1) a search for better and lowerdosage products; (2) a detailed investigation of the possible long-term effects of these compounds on various organs and body functions, and the determination of the safety, or lack of safety, of many years of consistent use by the same individual.

Since most women now using these products generally take them for family-planning purposes rather than to avoid any further pregnancies, data on long-term continuous use are not easy to obtain. In our clinic the number of women who have used any of our oral contraceptive preparations for over five years continuously is less than 300 , and our studies, with those of Pincus, constitute the longest investigations of this form of contraception. Therefore the total number of continuous users for over five years anywhere is likely to be very limited. It is important that long-term data about continuous use be obtained, because, as this form of contraception is being employed more and more by younger women, we will have millions who may complete their families between the ages of 25 and 30, and they will be depending on the continuous use of these products for another 15 to 20 years.

The detailed blood-chemistry studies we have referred to in this report provide one method of obtaining needed information regarding safety. One problem in obtaining this type of information is that certain abnormalities may be found, and they are not necessarily suggestive of pathology. This may hold particularly true, for example, for such changes as elevations in protein-bound iodine. One would be rash, I believe, in deducing a state of hyperthyroidism because the proteinbound iodine in a patient exceeded the usual normal limit of $8 \mu \mathrm{g} . / 100 \mathrm{ml}$. We therefore have to attempt to correlate any changes in chemical findings with the overall physiological alterations occurring during use of the oral contraceptives. This task of obtaining the data, finding suitable controls, and making the necessary correlation is not an easy one. We would like to extend our thyroid-function tests to those studies employing radioactive material, but this presents a problem when pregnant "controls" are used.
We are currently also finding stumbling-blocks in discovering suitable tests for adrenocortical function that can be employed readily in pregnant patients, with no medical or medico-legal risk. Fortunately, the reputable pharmaceutical manufacturers involved with these preparations, as well as various research organizations, are anxious to obtain all the information possible, and there is little problem regarding support in this respect. It is likely that, despite the obvious obstacles, the next few years will bring about an elucidation of the manifold effects that progestogen-oestrogen contraception may have. So far, we know they are extremely effective and we have no definite evidence of serious toxicity. We also know that it requires very small amounts of these agents to provide efficacious contraception. In the case of norethisterone the dose is now down to $2 \mathrm{mg}$. (with $0.1 \mathrm{mg}$. of mestranol), and the minimal effective dose may even be lower, a matter we are now in the process of investigating.

\section{Summary}

A brief review of eight years' study of oral contraception is given. Reference is made to detailed blood-studies carried out on patients using various preparations, and a discussion of certain of the findings is presented. In general, while some chemical factors were altered, it is very possible that these are not evidence of a pathological change, but, rather, may be attributable to the pseudopregnancy state. These studies are being continued and expanded.

An analysis of over three years' study of the 2-mg. norethisterone product is also presented. In 6,455 cycles of use by 435 patients side-effects were minimal and there were no pregnancies.

\section{REFERENCES}

Goldfarb, A. F. (1964). In Advances in the Treatment of Menstrual Dysfunction. Lea and Febiger, Philadelphia.

Henstell, H. (1963). Proceedings of Conference on Thrombophlebitis. Chicago, III. Searle.

Proceedings 4th International Planned Parenthood Congress, Singapore, Feb. 1963.

Samuels, A., and Lepowsky, F. (1963). Int. 7. Fertil., 8, 665.

Tyler, E. T. (1963). I. Amer. med. Ass., 185, 131.

(1964). Ibid., 187, 562.

and Olson, H. J. (1958). Ann. N.Y. Acad. Sci., 71, 704.

- (1959). F. Amer. med. Ass., 169, 1843.

- Gotlib, M., Levin, M., and Behne, D. (1964). Clin. Med., 71, 997.

M. Wolf, L., Finkelstein, R. N. S., Thayer, J., Kaplan, N., Levin, M., and Weintraub, J. (1961). Obstet. and Gynec., 18, 363.

\title{
Use of a Modified Minicoil for Continuous Dialysis
}

\author{
D. J. BLACKMORE,* M.I.BIOL. ; G. MITCHELL, $\dagger$ M.B., CH.B.
}

Brit. med. F., 1964, 2, 847-850

Management of acute renal failure may include the use of artificial kidneys with dialysing areas varying between 0.4 and 3.2 sq.m. to supplement conservative regimes. Dialyses may be carried out at varying intervals, but recent trends have been for earlier and more frequent dialysis.

This preliminary communication presents a report of modifications to a small dialysing apparatus with a dialysis membrane

* Pilot Officer, R.A.F., Research Department, Institute of Pathology and Tropical Medicine. Present address: Department of Pathology, R.A.F. Hospital, Steamer Point, Aden. B.F.P.O. 69

† Squadron Leader, R.A.F., Srecialist in Medicine, Renal Unit, Princess Mary's R.A.F. Hospital, Halton, Aylesbury, Bucks. of viscose cellulose tube $4.4 \mathrm{~cm}$. wide by $5.14 \mathrm{~m}$. long producing a surface area of 0.45 sq. $\mathrm{m}$. marketed under the trade name of Minicoil (Lawson et al., 1962) and of its use in a modified form for continuous dialysis.

The manufacturer's description of the Minicoil includes the following points: "The coil unit is welded into a P.V.C. envelope which assumes an almost spherical form when distended with dialysis fluid ; this ensures an even perfusion of the dialysis membrane without leakage round the periphery of the coil. ... The entire unit is suspended from a moulded hanger via a flap which also serves the purpose of anchoring the constant-level device on one side and the blood filter and air-trap on the other." 